\title{
La antigua ceremonia de las doncellas Cantaderas en León
}

\section{INTRODUCCIÓN}

Aunque hace más de diez años que me interesé por la fiesta de las Cantaderas, pasó el tiempo y arrumbé el tema por diversas vicisitudes, ahora que lo he vuelto a desempolvar he encontrado nueva bibliografía sobre el asunto. La tesis de M. ${ }^{a}$ Isabel Viforcos es lo más señalado ${ }^{1}$, ella centra su estudio en la instrumentalización ideológica de la fiesta Barroca y dedica los diferentes capítulos a diversas fiestas leonesas, siendo el primero para las Cantaderas. Me ha interesado por la cantidad de documentación que brinda, pero mi investigación sigue una línea muy diferente.

Trataré de aproximarme a la simbología de la fiesta y me centraré en el significado de la Asunción y la danza sacra. En primer lugar daré cuenta de las descripciones que de ella hacen Atanasio Lobera y Francisco López de Úbeda, complementadas éstas con datos del Archivo Catedralicio a lo largo de los siglos XVI, XVII y XVIII. Una "longue durée" que se corresponde con la Edad Moderna, época en la que esta festividad llega a su cenit, y a la que sigue el decaimiento, debido a los grandes cambios económicos, políticos y sociales producidos a lo largo del siglo XVIII y principios del XIX.

La fiesta de las Cantaderas es un complejo ritual en el que se acumulan diversos argumentos relacionados con el ciclo vital, el ciclo anual y con acontecimientos histórico legendarios. La analizaremos como un ritual de paso de unas jóvenes doncellas al que se yuxtapone otro que es la conmemoración de la muerte de la Virgen. Al coincidir con la época de la cosecha enlaza con el folklore y las festividades agrícolas. Las explicaciones que dan sentido a todo ello son la liberación del Tributo de las Cien Doncellas y la doctrina que subyace en la creencia de la Asunción. Siendo la danza de las Cantaderas la acción primordial del rito.

En resumen, se trata de un rito de iniciación (Cantaderas) al que se asocian argumentos teológicos (Asunción), legendarios (Cien Doncellas) y celebraciones anuales folklóricas de carácter agrícola; de tal manera que

1 M. I. VIforcos, La ciudad de León en el siglo XVII: La fiesta Barroca y su instrumentalización ideológica (León, 1991. Tesis doctoral en microforma). 
al rememorar la entrega de las vírgenes cristianas a los moros se actualiza y transforma en el tránsito de unas jóvenes que son presentadas en la catedral el día de la Asunción.

\section{DESCRIPCIÓN}

Las fuentes de mayor interés son: el llamado Cuaderno de Cantaderas perteneciente al Archivo de la Catedral de León con número 5.992 y un libro titulado Historia de las Grandezas de la Ciudad y Iglesia de León... escrito por Atanasio de Lobera y publicado en 1596. El primero es una recopilación de litigios y cuentas relacionados con esta ciudad desde 1501, información que llega hasta mediados del siglo xviII, si bien el manuscrito mantiene la letra del siglo xviI. Por contener información de primera mano sobre la organización de la fiesta y sus actuantes resulta de gran interés. La obra de Lobera, aparte de relatar la historia de la ciudad, de sus santos y obispos, hace una descripción completísima de todo el ceremonial de la fiesta tal como se realizaba en 1595 , con noticias directas ${ }^{2}$.

Estos dos documentos posiblemente no sean los primeros o más antiguos escritos acerca de tal celebración, pero no me interesa remontarme a sus orígenes inciertos, sino simplemente adentrame en su historia, para poder tener elementos de análisis y diferentes fuentes.

Otras informaciones para cubrir este período de tiempo (siglos XVI al XVIII) son las aportadas por la descripción que se hace de la fiesta en la La Pícara Justina de López de Úbeda y publicada en $1605^{3}$. Parte de esta novela picaresca discurre en León, por lo que hallamos numerosas descripciones de sus edificios, costumbres y fiestas. El capítulo $2{ }^{\circ}$ de la II parte se dedica a la danza de Cantaderas, el comentarista de la edición que he manejado dice en una de sus notas: "López de Úbeda, que visitó León en febrero de 1602, no pudo presenciar sus fiestas de agosto. No se trata, pues, de una experiencia personal de las mismas, sino de la recreación a partir de una obra que describía pormenorizadamente estas celebraciones..." ${ }^{4}$. Se refiere a que copia el libro de Lobera, pero no creo que sea cierto, pues aporta datos diferentes e incluso contrarios, como después veremos.

Cristóbal Pérez Pastor hace referencia a que un 8 de mayo de 1640 se contrataba a un autor de comedias para que se representaran en León

\footnotetext{
2 A. Lobera, Historia de las Grandezas... de la Ciudad y Iglesia de León... (Valladolid, 1596), fol. 215.

3 F. LÓPEZ DE ÚBEDA, La Pícara Justina (Madrid, 1977), vol. II, pp. 399-407.

4 Ibid., p. 400 nota 59.
} 
el 15 de agosto y los días sucesivos, hasta seis veces y se le pagara 3.400 reales ${ }^{5}$. Lo cual verifica que en el siglo Xvil seguían haciéndose comedias para la Virgen de agosto.

Un documento que por su nombre promete más de lo que realmente da, es el Resumen de las Políticas Ceremonias; en él se nos pone al corriente del protocolo seguido en las fiestas de la ciudad de León; se dice en el capítulo XII: "Tiene la ciudad por costumbre y devoción desde la gloriosa batalla de Clavijo, que venció nuestro insigne rey don Ramiro, celebrar la festividad de nuestra Señora de la Asunción, que es a quince de agosto, y el día después de San Roque se corren lo toros.... ${ }^{6}$. Y al día siguiente de esta corrida da noticias detalladas de la salida de la Ciudad hacia la catedral, en el capítulo XV:

Sale la Ciudad en forma, de sus casas, con sus clarines, y tambores, y va a la iglesia mayor, y dando vuelta al Claustro, llega a una imagen que está de relieve, muy antigua, en un arquito del lienzo de el dicho Claustro, como entramos a mano izquierda; yendo delante las Niñas, que en remembranza de las Cien Doncellas dan todas las parroquias, lo más bien adornadas que les es posible; y asisten a la Iglesia desde las vísperas de la Asunción hasta esotro día acabada la misa, y en este del ofrecimiento, sólo asisten las de San Marcelo; ofrécese a dicha imagen, un cuarto de uno de los toros, y diferentes frutas... ?

En los Libros de Acuerdos del Ayuntamiento de León se dice que, a principios del siglo XVIII, todos los años, la ciudad daba 600 reales para la función de las Cantaderas y una arroba para la luminaria del Santísimo de la iglesia de San Marcelo ${ }^{8}$.

Según Lobera la fiesta comienza con sus vísperas, a las que cuatro parroquias de la ciudad llevan doce niñas de entre 10 a 12 años, diestras en bailar y danzar. Cada niña porta dos ciriales muy enramados y en ellos sus velas para ofrecer a la Virgen. Van también dos atambores de guerra los cuales son sacudidos con fuerza y hacen mucho ruido, entran las cuatro parroquias en la catedral hasta la capilla mayor, danzando las niñas y precediendo las de San Marcial. Las Cantaderas hacen reverencias y callan los atambores, entonces bailan al son de un salterio en medio del coro. Luego pasan al altar mayor, al lado del cual está el obispo en su sitial vestido de pontifical. Le besan la mano y reciben su bendición,

5 C. PÉREz PASTOR, Nuevos datos acerca del histrionismo español (Madrid, 1901).

6 F. CABEZA DE VACA, Resumen de las Políticas Ceremonias... con que se gobierna la Ciudad de León... (León, 1978), pp. 29-30.

7 Ibid., p. 36.

8 Libro de Acuerdos del Ayuntamiento de León, años 1704, 1706, 1708 y 1711. 
después bailan de dos en dos en la grada superior y salen del coro. Al ponerse el sol comienzan una Salve fuera de la iglesia en el patio primero, delante de una imagen de nuestra Señora la Blanca. Asiste a ella el Obispo, el Cabildo, clérigos, religiosos, Regimiento, la Caballería y el pueblo. Al anochecer en la plaza de la Regla se hacen fuegos de artificio, luminarias, hogueras y tocan ministriles con trompetas.

El 15 de agosto al salir el sol, va el Corregidor con la Caballería y estandartes a oír la misa al mismo lugar donde se cantó la Salve y luego corren por la plaza con sus caballos. Antes de la misa mayor hay procesión solemnísima por la iglesia y claustro, capitulares con capas de brocados y obispo de pontifical. Al salir la procesión entran las doncellas igual que el día anterior, al llegar a la puerta de Ntra Sra del Dado, las de la parroquia de San Marcial ofrecen al obispo un canastillo de peras y otro de ciruelas, vuelve la procesión al coro y se celebra la misa. Concluyendo ésta se representa en la plaza de Ntra Sra la Blanca una comedia y otra a la mañana del día siguiente. La ciudad como quiere celebrar esta memoria instituyó la Cofradía de Santiago, por esto sacan en Santiago y en la Asunción el pendón con sus imágenes y armas y dicen misa cantada.

El 17 de agosto las cantaderas a las diez de la mañana van a la iglesia llevando delante un carro tirado por bueyes y en él un toro muerto, los cuernos de los bueyes van adornados con roscas de pan y las "mollidas" aderezadas con ricos fruteros y toallas. Y en los últimos va el Regimiento de la ciudad, así entra el carro en la iglesia dando vuelta a la capilla mayor y sale al claustro. Y llegando a una imagen de la Virgen ofrecen las de San Marcial el toro y un cestillo de panecillos pequeños y otro de ciruelas y peras. Los representantes del pueblo dicen que "la ofrenda la hacen por devoción y no por fuerom. A su vez los representamtes eclesiásticos dicen que la "reciben por fuero y no por devoción". Concluido esto se va el Regimiento con sus bailes.

Advertí que delante de las donzellas cantaderas de la parrochia de San Marcial, yva danzando, con grandes demostraciones de contento, una mujer anciana, cubierta con tocas moriscas, y una rueda en la cabeça a manera de gitana. Preguntando qué mujer era, y qué significaba, no me supieron decir más de que aquella era la sotadera... 9 .

Se trata pues de una celebración de la Asunción de María en la que el hecho principal es una danza de niñas cantaderas comandadas por una mujer mayor llamada sotadera. Es una festividad solemne y popular con ciertos aires grotescos, como descubriremos más tarde, digo que es solem-

9 A. LOBERA, op. cit., fol. 223. 
ne porque está organizada y sufragada por la ciudad, tomando parte el poder religioso y el civil. También es una fiesta en la que están involucrados muchos leoneses de diferentes condiciones y rangos.

Por el Cuaderno de Cantaderas consultado en la catedral, conocemos vicisitudes de la festividad que en esa época se realizaba con algunos pequeños inconvenientes pero asiduamente, debidos a la falta de algunas ofrendas o personajes, lo que nos indica que las cantaderas tenían gran arraigo. Se sabe que, en el siglo xvI, las cantaderas ofrecían candelas y cirios blancos y amarillos en el XVII. En el año 1671 se plantea un problema grande al no haber acudido las Cantaderas con la sotadera el día de la entrega del toro (17 de agosto):

Y las de la parroquia de San Marcelo tienen obligación a traer su mayordomo una mujer mayor con su arco en la cabeza a modo de çeranda cubierta con su tafetán y por encima del muchas joyas que viene convoyando las niñas y llegando a esta Sta Iglesia baylan de dos en dos al pie del altar mayor... ${ }^{10}$.

También sabemos que la procesión entraba al claustro de Ntra Sra de Regla por la puerta de Gomia. Se da cuenta de que a la gente que esperaba en la plaza le tiraban peras, ciruelas, avellanas y panecillos. El toro que se ofrecía era de los que se habían corrido el día antes. En 1745 se dice que el ofrecimiento de frutas se hace ante una imagen de Nuestra Sra. llamada la Preñada.

López de Úbeda desdice de alguna manera a Lobera, pues comenta que las Cantaderas eran "pollas" de entre 18-20 años, y sabemos que a finales del siglo XVI eran más jovencitas. Además, da un aire satírico y burlesco a la celebración que contrasta con la imagen de Lobera y que enlaza con la documentación del litigio que surge ya en el siglo xviI y que acaba por trastocar la fiesta en el siglo XIX. Fijémonos en lo que dice de la sotadera:

la cosa más vieja y mala que vi en toda mi vida, que me parece que para purgar una persona y digerir hígado y livianos y todos los entresijos, bastaba enjuagar dos veces los ojos o la cara de aquella maldita vieja cada mañana... ${ }^{11}$.

El autor de La Pícara Justina resalta aspectos problemáticos de la fiesta, como la edad de las Cantaderas, la zaranda y velo de la sotadera y también la duda de si muchachas de aquella edad pudieran o no ser vírgenes, haciendo alusión a las chanzas y habladurías a que llevaba esto en el transcurso de la celebración.

10 Archivo Catedral de León Cuaderno de Cantaderas, manuscrito 5.992, año 1671.

11 F. LOPEZ DE ÚBEDA, op. cit., p. 406. 
El mismo Lobera alude a estas cuestiones espinosas:

Es tradición que estas vírgines (que salían en público a celebrar la fiesta) eran ya mugeres casaderas, y las más nobles y principales de la ciudad, y que juntamente dançavan y cantavan. Ya esto cessó, por algunos inconvenientes, que se siguieron, y se a reduzido a niñas de poca edad ${ }^{12}$.

De este comentario deducimos que la fiesta contenía elementos que provocaban tensiones, burlas y tal vez escándalos... Quizá esto era debido a la relación del ritual con la sexualidad femenina, mozas casaderas que se suponen vírgenes que van a cambiar de papel. Debido a ello se sustituyeron por niñas para no provocar desórdenes. Las niñas de 10-12 años pueden estar más relacionadas con un paso catamenial, de impúberes a púberes, pero ya no al paso del matrimonio y de la vida conyugal.

De todas maneras la festividad continuó provocando escándalo; así lo indican unas Actas de $1813^{13}$, en ellas se dice que las niñas no concurrían de manera edificante, causaban irrisión y motivos de befa, especialmente por varios personajes: los atabales, salterios y sotadera, a los que se consideraban personas despreciables.

Tras el lapsus de la Guerra de Independencia y desde 1813 hasta 1826 Ayuntamiento y Cabildo litigan acerca de la obligación de llevar las niñas a la Catedral, porque resulta oneroso para las parroquias y termina por no ser obligatorio llevar las cuatro parroquias las Cantaderas todos los años.

El Ayuntamiento se hace eco de lo poco edificante del recuerdo del Tributo de las Cien Doncellas y pide buscar "otro concepto más decoroso y piadoso". Ha habido cambio de mentalidad y lo que durante dos o tres siglos ha sido una costumbre obligada, llega a cuestionarse por razones económicas y morales. La Ilustración y la Guerra contra Napoleón no han pasado en balde, los tiempos han cambiado. La danza de las Cantaderas seguirá haciéndose pero con otros presupuestos.

\section{ANÁLISIS}

Las ceremonias y fiestas son o suelen ser acontecimientos farragosos con muchos actos y sucesos concatenados, y a veces paralelos y casi ininteligibles para los extraños. Los etnólogos y folkloristas han tratado de desentrañar su hermenéutica con mayor o menor acierto. Un avance se produjo a principios de siglo cuando Arnold van Gennep desveló la suce-

\footnotetext{
A. LOBERA, op. cit., fol. 222.

13 Actas del Cabildo y Ayuntamiento de León de 1813 a 1826.
} 
sión de los rituales iniciáticos. A partir de su estudio conocemos un poco mejor la esencia de muchas ceremonias al poseer su esquema formal: separación, margen y agregación.

En mi trabajo he aplicado este análisis de las sucesiones, muy eficaz porque ordena la fiesta de una manera significativa. Las Cantaderas son elegidas cada año entre las muchachas de una determinada edad, en cada una de las cuatro parroquias principales de León (a saber San Marcelo, Santa Ana, San Martín y Ntra Sra del Mercado). Cada parroquia aporta entre 10 y 12 niñas. Este momento es el llamado de separación, porque se elige o selecciona a unas cuantas, en él son adiestradas durante dos o tres meses en la danza... no sabemos si en alguna otra cosa. Para la festividad de la Asunción de la Virgen participan como parte principal en el ritual y ofrenda en la catedral durante tres días seguidos, este es el período de margen o limen que incluye procesión y danza en el templo, bendición del obispo, ofrenda de candelas a la Virgen, cestillos con panes y frutas, además de un cuarto del toro. Finalmente, vuelven a sus parroquias, a sus casas, se incorporan a la vida cotidiana que es lo que consideramos período de agregación, en el que ya pertenecen a un nuevo grupo de edad.

Analizaré con especial atención la fase liminar o de margen que es la que se corresponde con el ceremonial y danza que tiene lugar en la catedral y sus aledaños, los otros dos estadios se nos escapan, tal vez porque al ser menos vistosos y tener un carácter particular e individual se conocen menos. De todas maneras el periodo liminar en nuestro ritual es el más desarrollado, por tanto el más importante.

En primer lugar daré cuenta del sujeto de este rito de paso: las Cantaderas. Eran en aquella época niñas de 10 a 12 años, llevadas al templo para demostrar que habían llegado a lo que van Gennep llama pubertad social, porque no es exactamente la pubertad fisiológica sino un grupo semejante por la edad cercana al hecho catamenial, y por ello con mucha seguridad vírgenes, que es lo que se necesitaba para la fiesta. Es una ceremonia de iniciación y no un rito de pubertad lo que analizamos. "En Roma las chicas son legalmente núbiles a los 12 años, pero sólo la duodécima parte de las jóvenes romanas tiene sus reglas a esa edad: la inmensa mayoría no las tiene hasta los 14 ó 15 años y algunas, excepcionalmente, desde los 9 años" ${ }^{14}$. Las jóvenes Cantaderas van especialmente vestidas con brocados y sedas, engalanadas con joyas de oro, plata, perlas y piedras preciosas, sabemos que resultaba gravoso para los padres arreglarlas de esta manera. Eran especialmente adiestradas en bailar, pero también se buscaba las que tenían condiciones para ello, además cantaban, según comentario de Lobera.

\footnotetext{
14 A. VAN GenNeP, Los ritos de paso (Madrid, 1986), p. 80.
} 
Junto a las Cantaderas, dirigiendo su danza de manera ostentosa, venía la sotadera. Considero a la sotadera uno de los instructores de las neófitas, a nivel simbólico la principal, porque comanda o convoya el baile. La sotadera es un personaje que estuvo vinculado con la juglaría ${ }^{15}$ por tanto con significación festiva y ritual. Pero también es un personaje asociado a la vida licenciosa, relacionado a otras etnias marginadas como la mora o la gitana. Lobera hace relación a su vestimenta gitana y a su condición morisca algo ambigua. Tenemos indicios de que la indumentaria y tocado de la sotadera era el que comúnmente utilizaban las prostitutas y hechiceras moriscas medievales. López de Úbeda hace igualmente sus comentarios irónicos... "Sólo en una cosa vi que andaban bien los curas, que la mandaban a la sotadera cubrir el rostro con una manera de zaranda forrada en no sé que argamandeles...." ${ }^{16}$.

Su carácter ambiguo y radicalmente distinto de las Cantaderas es notorio: es mayor, fea, extranjera o de otra cultura. Pero organiza y comanda la danza, es la guía, guía moral por su edad y guía por el conocimiento de la lengua española, la danza y otros saberes que no son explicados. El hecho de guiar el baile tiene por tanto un contenido simbólico y otro estructural. Es propio de muchas danzas españolas el llevar un guía o líder que se puede llamar Mogigona en las mayas, o Mogigón en el Corpus Christi de Madrid, con elementos, además, de carácter ridículo y burlesco.

Julio Caro Baroja estudió las danzas leonesas organizadas bien por hombres o por mujeres en honor a la Virgen o a los Santos, y de ellas indica que: "El rasgo acaso más distintivo y curioso es el de la aparición de una especie de jefe de la danza que tiene caracteres medio terroríficos medio burlescos y al que se denomina de varias maneras y se viste de modo diferente" ${ }^{17}$.

Mircea de Eliade explica, acerca de los ritos iniciáticos femeninos de la India y África, "...bajo la dirección de las ancianas de la familia o de mujeres de avanzada edad. Dichas monitoras las instruyen acerca de los secretos de la sexualidad y de la fecundidad, enseñándoles las costumbres de la tribu y una parte al menos de las tradiciones religiosas: las accesibles a las mujeres" ${ }^{18}$.

Las alcahuetas y hechiceras utilizaban la magia erótica y durante siglos fueron perseguidas por la Inquisición, sabemos que antiguamente acaba-

15 R Menéndez Pidal, Poesia juglaresca y juglares (Madrid, 1983), pp. 30-34 y A. Bonilla, Las Bacantes o del origen del teatro (Madrid, 1921), pp. 56-57.

16 F. LÓPEZ DE ÚBEDA, op. cit., p. 407.

17 J. CARo Baroja, El estío festivo (Madrid, 1984), p. 161.

18 M. ElIADE, Iniciaciones místicas (Madrid, 1975), p. 76. 
ban como tales las mujeres de vida airada como única salida profesional a la vejez ${ }^{19}$. Pero también las viejas moriscas y las gitanas eran especialistas en hechicería erótica, y uno de los elementos propios de las hechiceras eran las habas y el cedazo: "El cedazo es [...] un típico instrumento mágico [...] pero si el cedazo es un instrumento de origen agrícola, los hechizos que con él se hacían llegaron a las artes, como otros muchos de humilde proveniencia" ${ }^{20}$.

Se puede entender que la sotadera llevara la cara tapada, por el hecho de tener una profesión mal vista que la aparta socialmente. La zaranda o cedazo que llevaba en la cabeza debe estar relacionado con su oficio de hechicera o ser un símbolo del virgo. Y ahora podemos preguntarnos iPor qué una vieja con aspecto burlesco es la guía de unas vírgenes que van a ser presentadas al templo? Ya hemos visto que en las danzas populares españolas suele haber un personaje ridículo y en aparente contradicción con el resto de los integrantes, las doncellas son el polo opuesto de la vieja hechicera, o prostituta. El estado liminar y anormal queda simbolizado en este personaje que representa a la iniciadora de las jóvenes. De una manera grotesca y exagerada las neófitas visualizan mejor los signos y símbolos de su cultura.

Víctor Turner en La selva de los símbolos tiene un capítulo dedicado al periodo liminar, titulado "Entre lo uno y lo otro", que nos ha ayudado mucho a comprender este ritual porque evidencia qué es lo esencial de esta cuestión: la comunicación de una sabiduría, el conocimiento de lo arcano, una gnósis. Y nos dice que este conocimiento se transmite por medio de lo que se denomina sacra, "Los sacra pueden comunicarse por: 1) exhibiciones, lo que se muestra; 2) acciones, lo que se hace; y 3) instrucciones, lo que se dice" ${ }^{21}$.

En mi estudio considero como objetos exhibidos los atambores y la zaranda; como acciones la danza, la bendición, la procesión y las ofrendas; y como instrucciones los sermones, las lecturas, los cantos y las comedias.

\section{Exbibiciones}

Lo que se muestra son objetos sagrados que se caracterizan por su simplicidad formal y su compleja interpretación. En la procesión marchan

19 J. Caro Baroja, Algunos mitos españoles (Madrid, 1974), p. 236.

20 Ibid., pp. 257-258.

21 V. TURNER, La selva de los símbolos (Madrid, 1980), p. 113-114. Esta clasificación está tomada de Jane Harrison que la aplica a los misterios órficos y eleusinos. 
dos atambores de forma ochavada, portados cada uno por dos jóvenes que los hacían sonar, incluso dentro del templo:

Van assímismo dos atambores antiguos de guerra, tan grande cada como una rueda de carro, aunque su forma es ochavada. Tiene cada atambor dos eslabones a los lados por donde lo llevan asido dos hombres. Sacúdenles con varas gruesas, tan rezio que hazen mucho mayor estruendo, que los atambores de guerra, que en este tiempo se usan. Tiénese por tradición, que son estos los mismos, que ganó en Clavijo el Rey don Ramiro ${ }^{22}$.

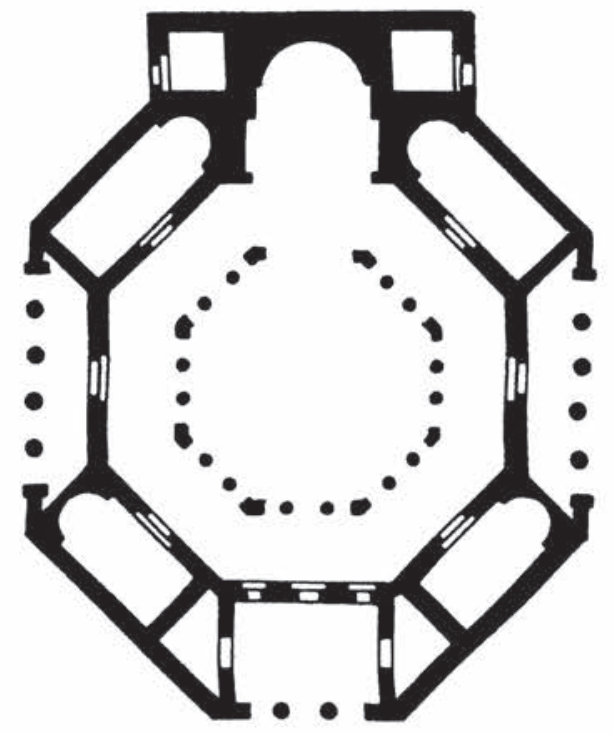

FIG. 1. Plano de la iglesia de la Virgen, Garizim.

Lobera advierte de la importancia de estos atambores y de lo que significaban, porque aunque eran como de guerra pero ochavados y extraordinariamente grandes y ruidosos, y su estruendo no importaba tanto, pues hacían referencia a aquellos ganados por Ramiro y eran motivo de alegría. Ya que los he considerado sacra debemos profundizar en su análisis y tomarlos como un objeto de reflexión, llegando incluso a su sentido metafísico.

La forma octogonal del atambor nos llama la atención y nos induce a hacer algunas consideraciones. El octógono es una figura geométrica de importante contenido simbólico en la arquitectura y pintura cristiana. La forma octogonal fue asociada con baptisterios, martirium y tumbas en los orígenes del cristianismo.

Baptisterios y pilas bautismales han tenido forma octogonal porque el número ocho se relaciona con la regeneración: el nacimiento por las aguas bautismales es el nacimiento a la vida en Cristo, y se asemeja y aproxima al nacimiento tras la muerte a la vida del espíritu ligada al martirio. El martirium poligonal fue originalmente un tipo de tumba tomada de la arquitectura sepulcral romana. Los antiguos teólogos cristianos interesados en la significación mística de los números, desarrollaron un simbolismo especial para el octógono en cuya forma vieron una correspondencia con el número de la salvación a través de la muerte y el principio de una nueva vida. Entre otras construcciones cristianas de los siglos IV al vi está la que se cree tumba de la Virgen en Jerusalén, también de planta octogonal, que fue un monumento sepulcral: "The octogonal memorial to

\footnotetext{
22 A. LOBERA, op. cit., fol. 216.
} 


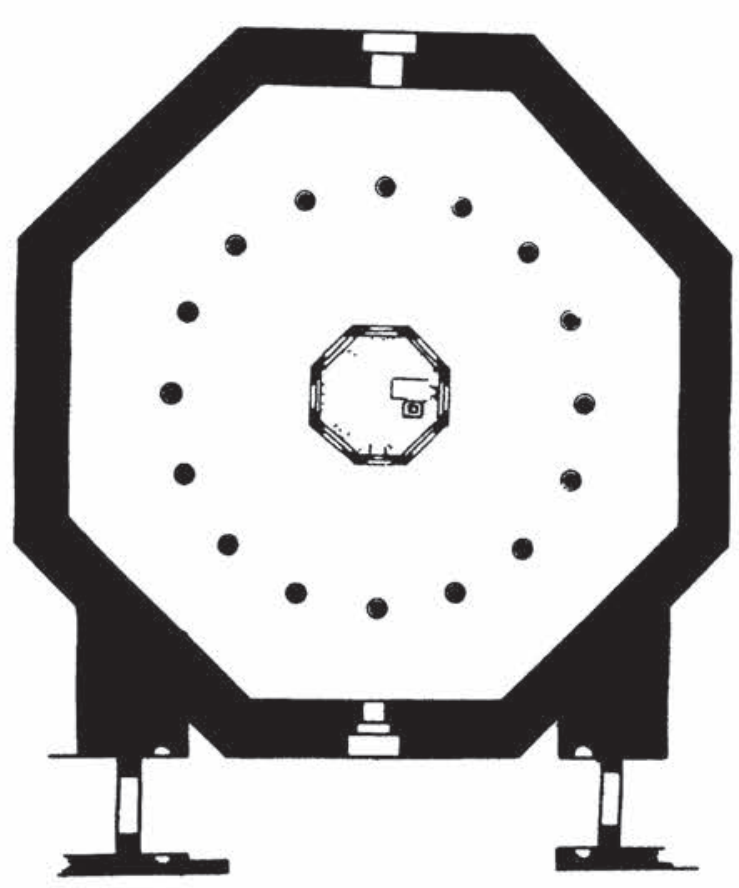

FIG. 2. Plano de la iglesia de la Ascensión, Jerusalén.

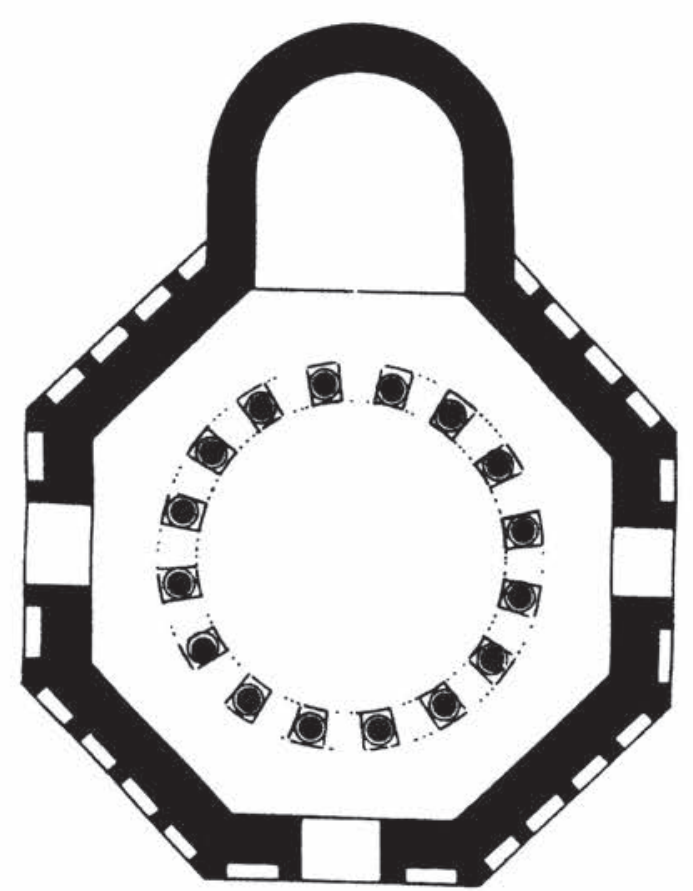

FIG. 2. Plano del Santuario de la tumba de la Virgen, Jerusalén.

the Virgin (fig. 161), construted in the imperial tradition, was built around the middle of the fifth century and had an interior colonnade with a diameter of 9 m.n ${ }^{23}$. El octógono va pues asociado a la muerte de María, de la misma manera que en la fiesta de las Cantaderas, la fiesta de su Asunción, dos atambores octogonales tocan en su templo.

Pérez Llamazares hace hincapié, en un artículo sobre la tradición mariana leonesa, en la antigüedad y hondura del asuncionismo leonés y en la importancia de las peregrinaciones a Jerusalén para visitar los Santos Lugares, entre los que figura el templo de la Asunción o sepulcro de la Virgen:

Esa riada de peregrinos a Tierra Santa con sus relaciones difundían por todos los confines del mundo cristiano los rayos de la tradición mariana de la Iglesia de Jerusalén, referentes al sepulcro de la Virgen, que ningún peregrino dejaba de visitar y en el cual estaba engarzado el dogma de la Asunción ${ }^{24}$.

También en la pintura encontramos fundamento para nuestra reflexión. Hay una imagen de la Asunción de la Virgen dentro de una aureola o círculo, rodeada de cuatro ángeles que la sostienen (miniatura de la Biblia de Ripoll llamada Farfa) ${ }^{25}$. Idealmente se consideraba igual una rotonda

\footnotetext{
23 B. SMITH, The Dome. A study in bistory of ideas (Princeton, 1978), p. 103.

24 J. PÉREz LlamazARES, La tradición mariana en León (León: Archivos leoneses, 1957), p. 62 .

25 M. TRENS, María. Iconografia de la Virgen en el arte español (Madrid, 1946), p. 49.
} 
circular que un octógono, Gregorio de Nisa describe como plano octogonal el formado por un "círculo con ángeles" ${ }^{26}$. También encontramos en varias representaciones de manuscritos antiguos leoneses (siglo $\mathrm{x}$ ) personajes sagrados envueltos en el círculo y sostenidos por cuatro ángeles, lo que supone un cuadrado al que se superpone un círculo, formándose una figura ochavada.

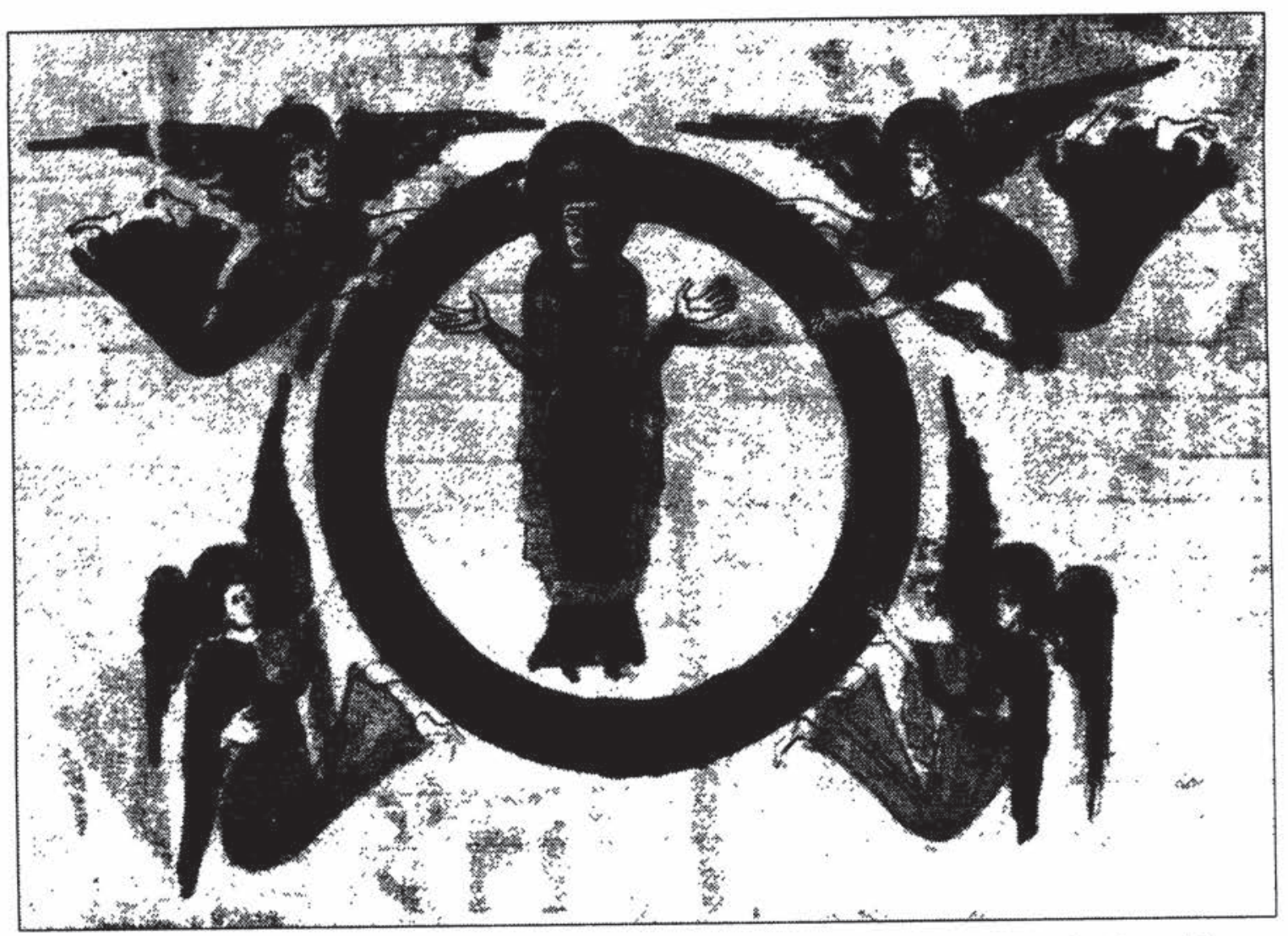

FIG. 4. Virgen en aureola que sostienen cuatro ángeles. Miniatura de la Biblia de Farfa (Fotogr. de la Biblioteca Nacional, Madrid).

Otro sacra sería el cedazo o zaranda que lleva la sotadera sobre su cabeza, el cedazo es un instrumento agrícola que sirve para separar las partes sutiles de las gruesas de alguna cosas (Diccionario de la Real Academia Española). Es claramente un símbolo, un elemento perteneciente a un contexto agrícola que traspasa su umbral y adquiere un valor sacro contextualizándose en un ritual de iniciación, donde también se va a separar y seleccionar cada año a las Cantaderas. La separación es el primer paso de la iniciación, hace pues alusión a lo primordial de la ceremonia: tamizar, depurar, perfeccionar, llegar a lo esencial que es el meollo de la cuestión.

El cedazo, vinculado a la sotadera, adquiere una perspectiva polivalente porque al valor agrícola yuxtaponemos su uso como elemento

26 B. SMITH, op. cit., p. 100. 
de hechicería amatoria, que es para lo que les servía a las viejas moriscas al estilo de la sotadera. De esta manera se disocia el elemento y nos hace reflexionar sobre él en los diversos contextos.

\section{Acciones}

Los primeros testimonios de bailes dedicados a santos son los que se celebraban en los aniversarios junto a las tumbas de los mártires. La danza expresa la alegría y el júbilo por los bienaventurados, por ello comenzó a bailarse en las iglesias. Los acontecimientos festivos a los que se vinculó fueron las bodas, los bautizos, funerales, aniversarios de la muerte de ciertos santos, algunas fiestas de María y muy especialmente por Pascua de Resurrección, misterio central de la religión cristiana. La danza manifiesta la idea de la armonía restaurada que se produce con la Resurrección de Cristo y la liberación del reino de la muerte. La danza también representa el orden cósmico.

En España existen y existieron multitud de fiestas en las que se danzaba en la iglesia, hay noticia de la de los Seises en la catedral de Sevilla desde el siglo Xv, y en la de Toledo, así como en otras provincias. Aunque en el siglo XviI hubo prohibición de tales expresiones en el interior de los templos, algunas siguieron celebrándose, en especial las dedicadas a María, otras se trasladaron al exterior según atestigua Bonnet:

C'est encore un usage qui subsiste en Espagne \& en Portugal, toutes les villes des Fêtes de la Vierge; les filles s'assemblent le soir devant les portes del Eglises de Notre Dame, \& y passent les nuits a danser en rond, en chantant des hymnes $\&$ des cantiques en l'honneur de la Vierge; ce qui etoit fort commun parmi les chrétien dans le primitive Eglise, comme je l'ai déja dit ${ }^{27}$.

En toda España aún podemos encontrar danzas relacionadas con la Virgen y especialmente en su fiesta de la Asunción, una de las principales festividades de María porque los santos nacen realmente a su vida eterna a partir de la fecha de su muerte. Así que desde muy antiguo encontramos celebraciones eclesiásticas más o menos populares en la iglesia; Backman hace alusión a algunas de ellas en un capítulo dedicado a las danzas populares, de las que destaca, siguiendo a Capmany, algunas de la zona mediterránea: se bailaba en las vigilias en Montserrat; en Aloro (Baleares) bailaban "les cosiers" junto con unos diablos y en Mallorca bailaban los "cociés" ${ }^{28}$.

27 J. BONNET, Histoire générale de la danse (Paris, 1724), pp. 50-51.

28 E. L. BACKMAN, Religion dances in the Christian Church (Westport, 1977), pp. 96-107. 
No conocemos con exactitud el tipo de baile de las Cantaderas en la catedral, sólo sabemos que penetraban en el templo las cuatro parroquias hasta la capilla mayor, danzando las niñas y precediendo las de San Marcelo. Hacían reverencias, callaban los atambores y entonces bailaban al son del salterio en medio del coro. Luego pasaban al altar mayor, recibían la bendición sacramental del obispo y bailaban de dos en dos por su orden en la grada superior (Lobera). Durante los otros dos días no se hace alusión al baile, sino a las ofrendas que se realizaban en el claustro principalmente. La danza no es solamente un regocijo celestial conectado con la armonía restaurada, sino que es la manera directa de acción contra el mal y consecuentemente contra los demonios. "The dance of the angels thus facilitates escape from the Underworld and ascent to Paradise" 29.

Los antiguos cristianos suponían que tan sólo los mártires llegaban al cielo sin necesidad del purgatorio o bautismo de fuego (especie de bajada a los infiernos) porque su martirio suplía con creces tal paso. La Virgen, aunque no recibió martirio, es reina de los mártires y en su tránsito al cielo se incluye, además del alma, su cuerpo. A nivel popular esta tradición se recogió en los apócrifos, y pasó con el tiempo al acervo común de la cristiandad europea en la ceremonias medievales que se celebraban el 15 de agosto, en las que principalmente se danzaba. La danza significaba la salida del reino de la muerte y servía para espantar a los demonios que pedían, tras la muerte de María, su paso por los infiernos. De hecho, ciertos apócrifos inciden en la petición de María a Cristo de no verlos. Igualmente anotamos que unos de los personajes de la danza de la Asunción son diablos: en Mallorca y Alaro (Islas Baleares) y en Francia, concretamente en la catedral de Rouen.

La misma tradición apócrifa y oral considera que María murió y resucitó al tercer día, uniéndose cuerpo y alma. Pasando así por las tres etapas iniciáticas que hemos aludido: segregación, en la que un ángel comunica en solitario la inminencia de su muerte y se rodea de los apóstoles que la velan; limen o margen que corresponde a la sepultura; y agregación o Asunción, cuando es recibida en cuerpo y alma en los cielos. Este hecho tan crucial en el credo del catolicismo, porque supone la resurrección de la humanidad encarnada en María, fue muy exaltado en las catedrales europeas pero especialmente magnificado en España. En León se vinculó con gran acierto el rito de paso de las mozas Cantaderas con el simbolismo profundo de la muerte y resurrección de María.

No sólo es una festividad vinculada a la Virgen y al ciclo vital de unas niñas, sino que también, como decíamos, forma parte del ciclo anual, el

$29 \quad$ Ibid., p. 47. 
15 de agosto ha sido la fecha que cerraba la recogida de la cosecha, la tierra ha dado su fruto que en este caso es ofrendado a la Virgen en forma de panecillo o también en cestillos de frutas y peras. La danza por supuesto ha estado unida a este tipo de celebración anual de exaltación de la naturaleza, imprecación para la consecución de la fertilidad y la abundancia. Las danzas que se realizaban a lo largo de la Edad Media en Europa tenían un contenido heroico, agrícola o sexual y estaban unidas al canto: diálogos, canciones. La fiesta de las Cantaderas fue con anterioridad a la época que habla Lobera, un ritual de mozas casaderas más en conexión con la fecundidad nupcial. Al organizarse como una ceremonia de niñas el carácter sexual se desdibuja aunque siga pesando.

\section{Instrucciones}

Víctor Turner nos dice que en las instrucciones los neófitos conocían el nombre de las deidades, la teogonía, la cosmogonía y la historia mítica conectada con los sacra. Así como también intervenían instrucciones éticas y morales y algunas reglas legales y de parentesco.

En el caso que nos atañe estas instrucciones, aparte de las dadas para la danza por las instructoras y la sotadera, se realizaban en las lecturas y sermones eclesiásticos, así como en los cantos y rezos. Por último, las comedias que se representaban estos días formaban parte del conjunto aleccionador. Creemos que los mensajes primordiales que se ofrecían a las Cantaderas eran los relativos a la leyenda del Tributo de las Cien Doncellas y a la Asunción de la Virgen.

La fiesta de la Asunción es de origen bizantino y es interesante saber que se tienen datos de la importación de esta festividad en el Antifonario de la Catedral de León. La solemnidad se comenzó a celebrar con procesión, bendición de ramos, plantas, hierbas y con representaciones dramáticas que seguían de cerca la tradición de los apócrifos. Para la Asunción hay sermones específicos de San Jerónimo, San Agustín y San Bernardo; el Papa León V en 1347 mandó celebrar también su octava. La fiesta de la Asunción según F. Cabrol se fundamenta en tres hechos: la muerte de la Virgen, su resurrección y la entrada triunfal en el cielo. Forma parte de los misterios gloriosos, como conclusión final de la trilogía la humanidad es coronada y glorificada en el cielo en la persona de María.

El Tributo de las Cien Doncellas, además de la celebración de León, forma parte de otras, localizadas especialmente en el norte de España: Sorzano, Clavijo y Albelda en Rioja y San Pedro Manrique en Soria, etc. Es tema de romances y muchas de las comedias que se celebraban en la 
fiesta de las Cantaderas la tenían, lógicamente, como argumento. Tras la batalla de Clavijo ganada por Ramiro I, rey leonés, no se volvió a pagar el Tributo a los reyes moros. Se restituye de nuevo el orden moral y legal interrumpido, según dice la leyenda, desde Mauregato. La monarquía ramirense devuelve el honor y la honra a los caballeros leoneses, según se canta en un romance leonés:

Iban las cien doncellas

que llorando se marchaban

A tierra agarena

A la gleba montañesa

a rescatar un tributo a mezquitas cordobesas. con el fuego que vos lleve, que $\tan$ sin honra nos tiene ${ }^{30}$

El fabuloso Tributo de las Cien Doncellas daba explicación a la danza de la catedral de León. Pero en el siglo xviII la crítica ilustrada negó la existencia de tal tributo, "presentándole como invención de menguados cronistas", de ello se hicieron eco el Ayuntamiento y las Parroquias de la ciudad que en el XIX no gustaban de dicho recuerdo. La explicación de un ritual mediante una leyenda más o menos ficticia es un hecho común. Es el mito que da significación al ritual, es el sentido que los leoneses daban a las Cantaderas en el Antiguo Régimen y que se quebró a finales del xviIl con el racionalismo de la Ilustración.

\section{CONCLUSIONES}

He intentado desentranar algo de lo que decían aquellos antiguos leoneses en su ceremonia de las Cantaderas, ciñéndome a los elementos rituales de carácter sacro y legendario. Soy consciente de que se debe ahondar más en estos símbolos y relacionándolos con el conjunto total de la procesión y del entorno histórico y social leonés, he seleccionado la parte que resultaba más complicada del ritual.

Me parece interesante resaltar la definición de la situación liminar de Víctor Turner como un estadio de reflexión. Contemplar este ritual como una instrucción es importante para la comprensión de los ritos de paso, porque lo analizamos como un aprendizaje muy mediatizado por los sentidos: los sacras que se muestran, la danza que se baila, más unas instrucciones que van a ser oídas y unas explicaciones de las leyendas e historias que sustentan el mundo tradicional.

Creo que la sotadera es el personaje central en esta danza, porque reune los elementos necesarios para protagonizar una situación de

\footnotetext{
30 M. Berrueta, Del cancionero leonés (León, 1971), p. 249.
} 
liminaridad por su carácter ambiguo y misterioso. La vieja mujer, que según Lobera era enviada por los moros porque sabía lengua española y servía para consolar y animar a las doncellas, rememora la antigua historia legendaria, pero haciendo un camino contrario, porque en el ritual las conduce al templo de María para exaltar su muerte y resurrección. Así que de su papel de mediadora entre moros y cristianos para conducir una situación de agravio se convierte, la sotadera, en reparadora de la honra perdida. María alcanza para el pueblo de León la gloria dañada. Los reyes de León vencieron sobre los infieles y ganaron su honra, la Virgen vence a la muerte y entra en el cielo en cuerpo y alma.

\section{CONCEPCIÓN ALARCÓN ROMÁN}

La fiesta de las Cantaderas, que celebraba el pueblo y la iglesia de León en su catedral el 15 de agosto (Asunción de la Virgen), era un ritual en el que se superponían y exaltaban una serie de eventos, de carácter tanto cíclico (anual-vital) como históricolegendario. En primer lugar, la describimos, a través de las fuentes histórico-literarias, en un período que se extiende entre los siglos XVI y XVIII. Después, la analizamos como un ritual de paso y especialmente como una situación de liminaridad, lo que nos ayuda a comprender la interconexión de todos los elementos rituales.

The feast of Cantaderas that the people and the Church of León celebrated in the Cathedral in August 15th (Virgin's Assumption), was a ritual in wich a series of events of both a cyclical (annual-vital) and historical legendary character were superposed and exalted. We start describing the feast through historical and literary sources, during a period that goes from the sixteenth to the seventeenth centuries. Then we consider the feast as a passage rite and especially as a liminal stage consideration that provides as with a better understanding of the relationship between all the ritual elements. 